\title{
EVALUATION OF SEISMIC VULNERABILITY ASSESSMENT PARAMETERS FOR PORTUGUESE VERNACULAR CONSTRUCTIONS WITH NONLINEAR NUMERICAL ANALYSIS
}

\author{
Javier Ortega ${ }^{1}$, Graça Vasconcelos ${ }^{1}$, Mariana Correia ${ }^{2}$, Hugo Rodrigues ${ }^{3}$, Paulo B. \\ Lourenço ${ }^{1}$, and Humberto Varum ${ }^{4}$ \\ ${ }^{1}$ ISISE, Department of Civil Engineering, University of Minho \\ Campus de Azurém, 4800-058, Guimarães, Portugal \\ \{javier.ortega,graca,pbl\}@civil.uminho.pt \\ ${ }^{2}$ CI-ESG Research Centre, Escola Superior Gallaecia, Portugal \\ marianacorreia@esg.pt \\ ${ }^{3}$ School of Technology and Management, Polytechnic Institute of Leiria, Portugal \\ hugo.f.rodrigues@ipleiria.pt \\ ${ }^{4}$ Civil Engineering Department, Faculty of Engineering, University of Porto, Portugal \\ hvarum@fe.up.pt
}

Keywords: Vernacular architecture, rammed earth, seismic vulnerability, parametric analysis, numerical analysis, Finite Element Method.

\begin{abstract}
Considering that vernacular architecture may bear important lessons on hazard mitigation and that well-constructed examples showing traditional seismic resistant features can present far less vulnerability than expected, this study aims at understanding the resisting mechanisms and seismic behavior of vernacular buildings through detailed finite element modeling and nonlinear static (pushover) analysis.

This paper focuses specifically on a type of vernacular rammed earth constructions found in the Portuguese region of Alentejo. Several rammed earth constructions found in the region were selected and studied in terms of dimensions, architectural layout, structural solutions, construction materials and detailing and, as a result, a reference model was built, which intends to be a simplified representative example of these constructions, gathering the most common characteristics.

Different parameters that may affect the seismic response of this type of vernacular constructions have been identified and a numerical parametric study was defined aiming at evaluating and quantifying their influence in the seismic behavior of this type of vernacular buildings. This paper is part of an ongoing research which includes the development of a simplified methodology for assessing the seismic vulnerability of vernacular buildings, based on vulnerability index evaluation methods.
\end{abstract}




\section{INTRODUCTION}

This paper addresses a critical gap in knowledge regarding vernacular architecture earthquake preparedness. It has been developed under the framework of the FCT funded research project 'SEISMIC-V: Vernacular Seismic Culture in Portugal', which focuses on the study of Local Seismic Cultures in Portugal and on the identification of adequate retrofitting techniques for vernacular buildings, empirically developed by local populations to prevent or repair earthquake damage [1]. The existence of Local Seismic Cultures was identified in the nineties by Ferrigni [2] and consists of the systematic efforts taken by local communities for protecting their built-up environment from earthquakes by the comprehensive ensemble of architectural elements with technical knowledge to efficiently reduce their impact. The study of Local Seismic Cultures is relevant because the continuity of traditional building systems and techniques is fundamental for the vernacular expression, and essential for its preservation.

Following this research line and results obtained from a preliminary report on the topic [3], Portuguese vernacular architecture is the case study also selected for this study (Figure 1). Portugal has a moderate seismicity but several devastating earthquakes have struck the country, as in 1755, 1909 and 1969 [4], and more are likely to occur in the future. Earthquakes come unexpectedly, endangering in-use vernacular architecture and the population who inhabits it. Most studies regarding seismic resistant Portuguese traditional architecture focus on 'pombalino' buildings [5], while research in vernacular architecture has been mostly focused on building typologies and spatial organization [6]. In the last years, there has been a growing interest on the experimental characterization of the seismic behavior of representative vernacular constructive systems [7-10]. Still, very little research has been made in terms of proposing strengthening solutions, particularly those emerging from the vernacular architectural heritage [11].
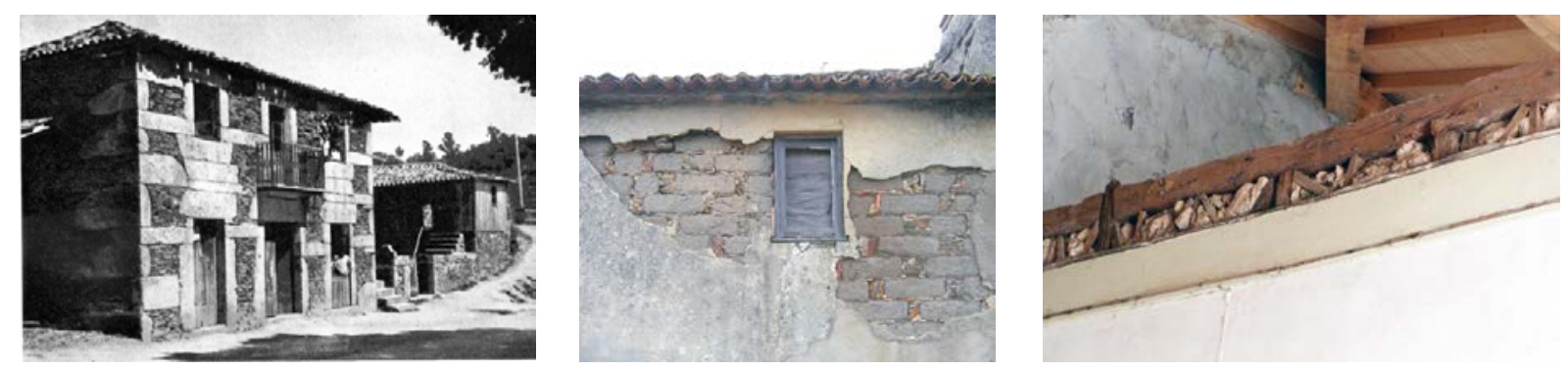

Figure 1: Examples of Portuguese vernacular architecture and traditional materials commonly applied: (from left to right) stone [6], earth [9] and timber

The valorization and preservation of the vernacular heritage is crucial, not only as a record of the past but also as a privileged factor of local development, boosting local economies [12]. The revival of small industries of traditional local materials, developed to be adapted to a specific territory and climate can also reduce waste and energy consumptions in production and transportation. In addition, and opposite to this current world's homogenizing tendency, vernacular architecture is extremely heterogeneous and constitutes and invaluable heritage throughout the world worthy of preservation and a key element of cultural identity. Nonetheless, due to this great variety of building types, work on the built vernacular heritage requires a deep knowledge and investigation of the place, the traditional techniques and materials, and should be cautiously approached in order to undertake a successful intervention. Moreover, the vernacular heritage has a dynamic nature and thus, it should not only be recorded and preserved but its constant evolution should be ensured. 
There is another undesirable effect resulting from this current global urbanization tendency, which is the replacement of traditional building materials and the adoption of new modern alien techniques and technologies which enable structures to be erected quickly and cheaply, but not necessarily safely [13]. This tends to increase the vulnerability of the communities because they do not have any more their own tools to prevent earthquake damage and become extremely dependent on external agents, circumstance which ends up diluting Local Seismic Cultures. Indigenous construction practices acquired from ancestors and experience are thus being gradually abandoned and replaced because local communities rely less on them [14]. An increase in knowledge in Local Seismic Cultures and in the seismic behavior of vernacular architecture is therefore justified because it can also prevent further changes in the existing buildings that contribute to the increase of seismic vulnerability by avoiding the usage of inadequate construction practices that can result from an inappropriate juxtaposition of old and new technologies.

This paper consists of an extensive numerical contribution for the better insight of the structural behavior of specific Portuguese vernacular architecture typology under seismic loading, and is part of an ongoing wider research aiming at contributing for the awareness and protection of the Portuguese vernacular heritage by reducing its seismic vulnerability with traditional strengthening solutions. For that purpose, one of the fundamental objectives embraced by the ongoing research was the development of a simplified methodology for the seismic vulnerability assessment of vernacular architecture.

This envisaged vulnerability assessment methodology aims at the identification of building fragilities, thus addressing an essential aspect in which the engineering research can intervene [15], since the evaluation of the seismic vulnerability of existing constructions can be used to evaluate the need of retrofitting solutions and to assess their efficiency in reducing the seismic vulnerability. In conclusion, this proposed methodology is planned to lead to the definition and optimization of building retrofitting strategies based on those traditional practices emerging from vernacular architecture, resulting from a Local Seismic Culture.

The seismic vulnerability of a structure can be defined as its intrinsic proneness to suffer damage as a result of a seismic event of a given intensity. Therefore, the main objective of vulnerability assessments is to measure the probability of reaching a given level of damage [16]. Given the big variety of methodologies proposed by different authors, choosing a certain seismic vulnerability assessment methodology will depend on the goal, scale and nature of the study and, additionally, it should always be adapted to the local techniques, materials and constructive solutions to account for the particularities of the regional construction.

The methodology proposed for this research is based on the vulnerability index methods, initially proposed by Benedetti and Petrini [17], which are based on a vast set of post-seismic damage survey data and on the identification of those constructive aspects that influence the most in the control of the seismic structural damage, i.e. plan and elevation configuration, quality of materials or state of conservation. This type of methodology has been already extensively used for masonry residential buildings in Italy [18] and in several Portuguese historical city centers $[10,15,19]$, obtaining useful and reliable results as a first level approach. Its main advantage is that they allow assessing the different constructions individually, based on their vulnerability characteristics, rather than evaluate the buildings solely as part of a building typology. However, the main disadvantage is that these potential seismic deficiencies are qualified and weighted according to their relative importance mainly through expert judgment and thus has a degree of uncertainty, which is not normally taken into account [16].

The determination of the seismic vulnerability index thus requires the identification and characterization of those parameters affecting the seismic response of the building and their qualification by points. Qualitative and quantitative parameters are defined and the 
vulnerability index is calculated as the weighted sum of these parameters, classifying the buildings according to their vulnerability. This index can be used to estimate structural damage after correlation to a specified seismic intensity, supported by post-earthquake recordings and statistical studies.

This paper presents a series of numerical nonlinear parametric analyses that were defined in order to assess and try to quantify the influence of the parameters initially selected for a representative Portuguese vernacular rammed earth construction typology chosen as a case study. This numerical simulation intends to understand in a more detailed way the resisting mechanisms of the different structural elements of this typology under seismic loading, based on these nonlinear static (pushover) analyses. Besides, finite element modeling based on nonlinear numerical analysis of rammed earth vernacular buildings represents a step forward in technical and scientific knowledge, as few results are available in literature.

\section{RAMMED EARTH CONSTRUCTIONS IN ALENTEJO}

\subsection{Selection of a case study}

A first vernacular typology was selected as a first case study, consisting of a type of vernacular rammed earth construction commonly found in the south Portuguese region of Alentejo. The choice of these vernacular constructions is twofold: (i) they can be encountered in regions that were previously identified as prone to have developed a Local Seismic Culture, such as Setúbal, Beja or Évora, where the seismicity is characterized by frequent earthquakes of low intensity; and (ii) traditional seismic strengthening solutions were already identified, such as buttresses, ties and timber reinforcements inserted within the rammed earth wall as a reinforcement (Figure 2).
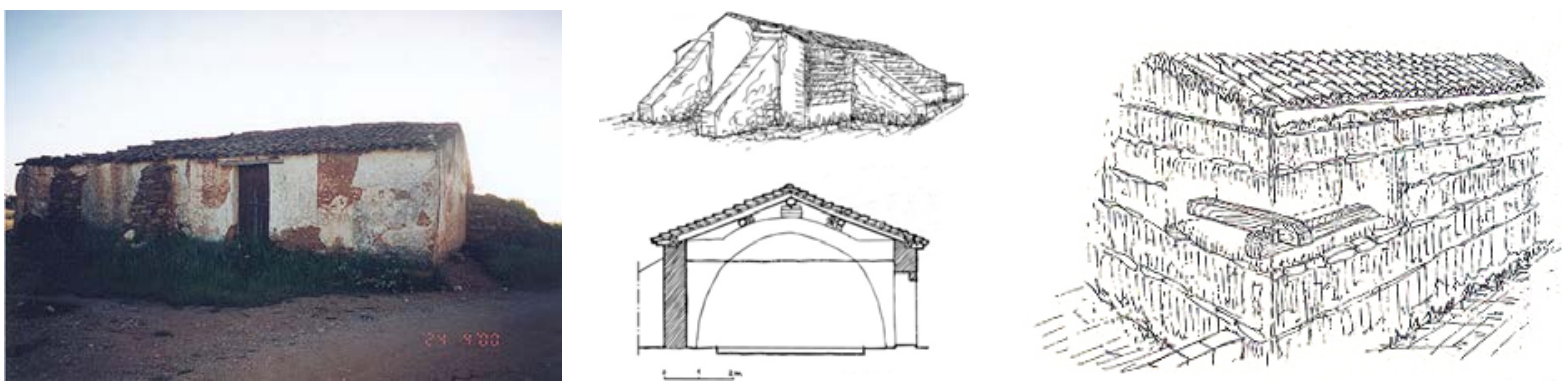

Figure 2: Traditional seismic strengthening solutions identified in characteristic rammed earth constructions of Alentejo [20]

Rammed earth construction, known as taipa in Portugal, consists of compacting the earth using a timber formwork for the construction of free standing walls. This has traditionally been the most widespread technique in these regions and, even though its use decreased significantly in the last forty years, is still in use in some places. These buildings have generally small dimensions, simple rectangular shape and only one floor, having predominant horizontal dimensions. They present massive shapes with few or no openings, other than a single door, and are isolated from other buildings. Other materials are also used, such as stone or brick masonry for reinforcing the corners and in order to build a base course or soco, which aims at protecting the rammed earth from the humidity and rain penetration by preventing the action of rising damp. The roofs are commonly mono-pitched roofs or gable roofs, usually presenting a low slope, and made with a simple framework of timber beams. The studied buildings can be found in 'Taipa no Alentejo' [20], which includes an extensive study of their geometry, structural solutions, construction materials and detailing. 


\subsection{Proposed parameters for the seismic vulnerability assessment methodology}

Developing specific and relevant seismic vulnerability assessment tools for this vernacular building typology is difficult due to its great heterogeneity, resulting from the uncertainty of many construction aspects, such as the constituent materials or different geometry configurations, often modified by previous structural or architectural interventions, among others. A methodology based on vulnerability index methods is proposed for obtaining an indicative measure of the seismic vulnerability, assuming that it can overcome this intrinsic heterogeneity by selecting qualitative and quantitative parameters that most influence their seismic response taking into account the particularities of this regional constructional typology so it will be particularly adjusted to this building typology.

The construction characteristics highly influence the seismic behavior of structures and the parameters were selected according to them. The selection was made mainly based on other parameters chosen in similar vulnerability assessments and on literature review of postearthquake damage observation [21-23], which is a decisive tool for the understanding of the structural behavior of vernacular constructions, since earthquakes are tests that prove the adequacy or inadequacy of construction practices and prove that the vulnerability does not rely solely on the age of a structure or the construction quality, but on many parameters. Table 1 shows the final parameters selected for this specific typology.

\section{Proposed parameters for the seismic vulnerability assessment methodology}

\section{Location and position within urban fabric}

P1: Location and soil condition

\section{Geometry: plan and elevation configuration}

P2: Plan configuration

3. Construction solutions and materials: vertical resisting elements (rammed earth walls)

P3: Distribution of resisting elements

P4: Wall slenderness

P5: Maximum distance between walls

P6: Rammed earth quality

P7: Connection between perpendicular walls

4. Construction solutions and materials: horizontal elements (roofs)

P8: Type of roofing system

\section{Opening characteristics}

P9: Number and area of wall openings

P10: Position and misalignment of wall openings

\section{Maintenance, previous damage, alterations and traditional strengthening solutions}

P11: Structural history of the building

P12: Non-structural elements

P13: Conservation state and previous damage

P14: Traditional strengthening solutions

Table 1: Vulnerability assessment parameters selected for rammed earth vernacular buildings in Alentejo

Most of the parameters selected are common to other vulnerability assessment methodologies, as they represent building features common to most of the typologies. For example, P1 (location and soil conditions) concerns characteristics such as the type of soil, foundations land slope, presence or absence of foundations and seismic micro-zonation of the building. P2 (plan configuration) accounts for the possible in-plan irregularities, which can enhance the torsional effects of the earthquakes and can be due to an excessive in-plan 
slenderness or an irregular shape configurations that leads to an eccentricity of the mass center with respect to the stiffness center. P3 (distribution of resisting elements) takes into account the conventional shear resistance of the walls, specifically addressing their distribution, since vernacular buildings usually present an irregular distribution and an unbalanced area of resisting walls in the two orthogonal directions, which may jeopardize the seismic resistance of the building. P4 (wall slenderness) measures the ratio between the effective height of the wall and its thickness, since the most slender elements are the most vulnerable to the seismic action. P5 (maximum distance between walls) measures the span to thickness ratio, since the longest elements without intermediate support are also more vulnerable to out-of-plane collapse. P7 (connection between perpendicular elements) takes into account the organization of the vertical structure system and the level of connection between perpendicular walls, which have a decisive role in the seismic behavior of the building, particularly at the corners. P9 and P10 concern the opening characteristics in terms of number and position, since the presence of many openings always indicates a potential vulnerability of the building, particularly if they are too close to each other or to the edges of the walls. P13 takes into account the degree of deterioration presented by the building, which is strictly correlated with an increase in the vulnerability of the building.

Nevertheless, some of these parameters are, as previously stated, specific of this typology. For instance, P6 takes into account the morphology of the vertical resisting elements, which in this case are rammed earth walls. An essential aspect of this parameter concerns the material mechanical properties, which are always difficult to measure and very variable in vernacular buildings, but have a decisive role in the seismic performance of the structure. A sensitivity analysis is foreseen in order to overcome the uncertainty resulting from the big variability of these properties that was observed in the literature. Not only the rammed earth properties but also the stone masonry properties need to be assessed because the buildings always present a stone masonry base course (Figure 3), whose influence should also be evaluated. Other constructive details that could be taken into account when assessing the influence of the morphology of the rammed earth walls in the seismic behavior are the horizontal brick courses that can be often found between the layers of rammed earth (Figure 3).

The type of roofing system (P8) should be assessed, firstly, in terms of the efficiency of wall-to-roof connections, which are commonly very poor in this typology and, secondly, in terms of the type of roof. Different type of roofs can be commonly observed applied in these buildings, which may have an influence on the seismic behavior of the building. Particular attention should be paid to the thrust exerted by some of these types.

The structural history of the building (P11) is also important in this typology because these buildings traditionally expands. These new parts are usually built in different materials and are poorly connected to the original building, which may increase the vulnerability of the building. Chimneys are the only relevant protruding non-structural element (P12) that can be systematically found in this type of buildings (Figure 3). The vulnerability of the building may increase according to the height of this element.
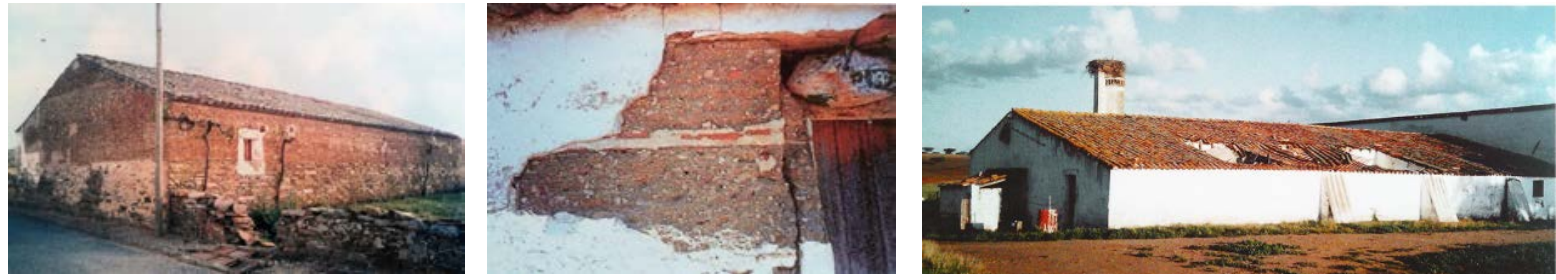

Figure 3: (left) Stone base course [20]; (middle) brick masonry horizontal course within rammed earth walls [20]; chimney [20] 
Finally, P14 accounts for those traditional strengthening solutions that have a direct influence on the seismic behavior of the building, such as buttresses, which is a common element usually observed attached to this type of buildings. This parameter only takes into consideration those techniques that do not have a direct influence over specific parameters, since some of these traditional techniques, i.e. ties, have a direct influence on other parameters selected, like the connection between perpendicular elements.

\section{REFERENCE NUMERICAL MODEL}

\subsection{Reference building geometry}

Resulting from the analysis of the buildings from the database found in the literature [20], a reference model was built, which intends to be a simplified representative example of these constructions, gathering common characteristics in terms of dimensions and architectural layout that are able to typify more precisely the rest of the buildings present in the database. The dimensioned plan and elevations of the reference building used are shown in Figure 4.

The plan has a simple rectangular shape, symmetrical in both orthogonal directions, regarding also the distribution of the interior load bearing walls. The height of this type of buildings rarely surpasses 3 meters at the front and back walls. The gable walls are not very high either, keeping the roof slope low, between 15-20 degrees. The height of the stone masonry base course is very variable but was established as 0.4 meters. Regarding the openings, the position of the two doors and two windows has also a symmetrical configuration. Timber lintels were considered over the openings, as this is also the common practice observed in almost every building of the database. Chimneys or other non-structural elements were not added to the reference building at this initial step.
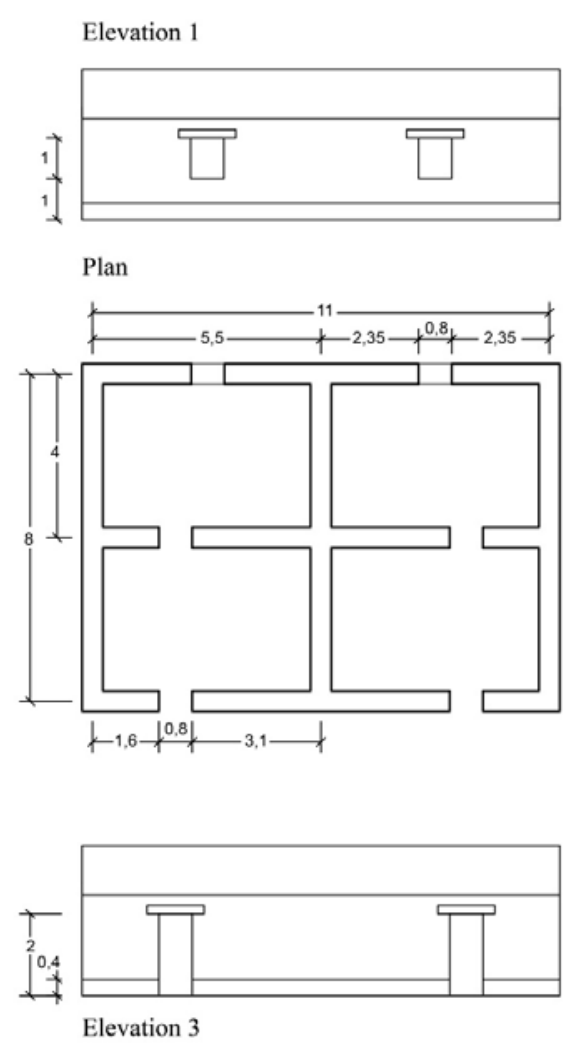
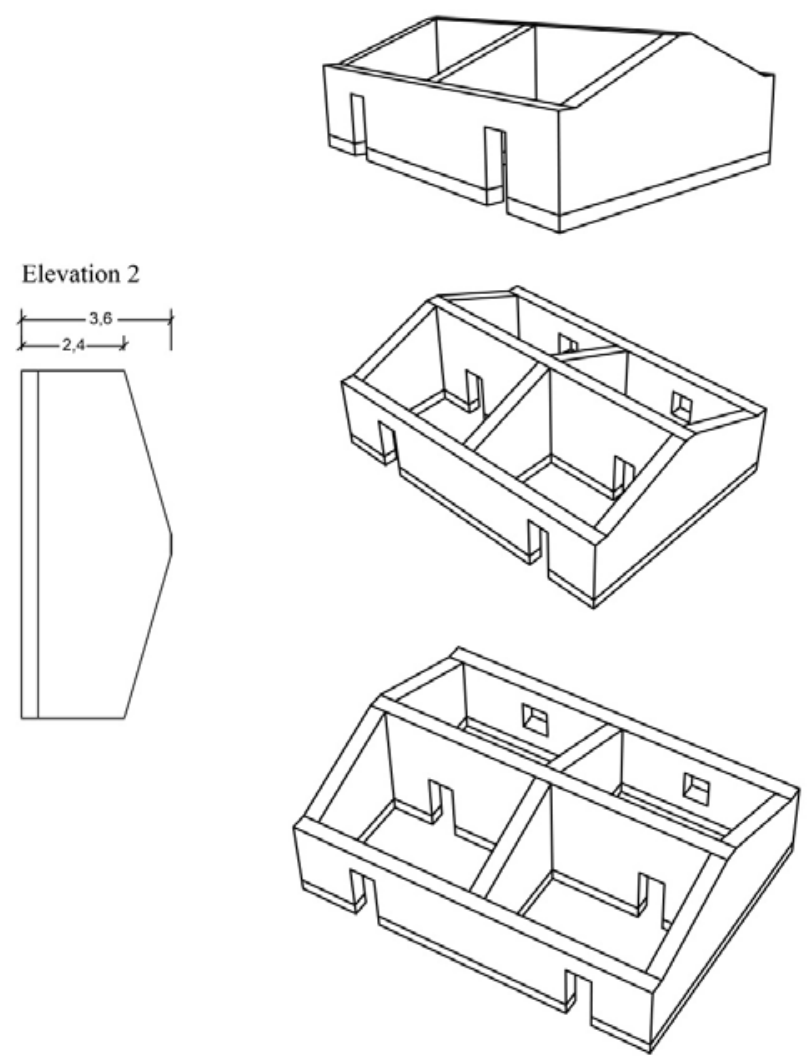

Figure 4: Plan and elevations of the reference building adopted for the construction of the reference model 


\subsection{Finite element model}

The numerical model was constructed taking into consideration the geometry of the reference building previously defined. With regard to the material properties and data, few studies have focused on the finite element modeling of rammed earth buildings [24-30], and most of them have adopted simple models, assuming simple constitutive laws, mainly linear elastic isotropic. However, in order to understand and simulate accurately the seismic behavior of rammed earth constructions, it is important to describe accurately the nonlinear behavior through more complex constitutive models, since relevant deformation of the structural elements is expected. Nevertheless, this requires detailed information of the mechanical properties of the material, which is not always possible. In this case, the material properties were obtained from data collected from different authors. A big variability was noticed, which brings up more uncertainties.

The material model finally adopted to represent the nonlinear behavior of the rammed earth in the analyses is a standard isotropic Total Strain Rotating Crack Model (TSRCM), which describes the tensile and compressive behavior of the material with one stress-strain relationship and assumes that the crack direction rotates with the principal strain axes. It was implemented in DIANA software [31]. An isotropic model was chosen because despite its layered structure, experimental tests found in the literature have shown that the mechanical properties of rammed earth do not behave in an anisotropic way and only has an influence on crack mechanisms [30]. This model is very well suited for analyses which are predominantly governed by cracking or crushing of the material. The tension softening function selected is exponential and the compressive function selected to model the crushing behavior is parabolic.

The model is built with solid 3D elements: (i) twenty-node isoparametric solid brick elements (CHX60) with three-by-three Gauss integration in the volume; and (ii) fifteen-node isoparametric solid wedge elements (CTP45) with a four-point integration scheme in the triangular domain and a three-point scheme in the orthogonal direction, used to adjust the mesh to the geometry resulting from the triangular gable walls.

Three different materials are considered. Stone masonry is used for the base course, which is usually built with an irregular schist or granite masonry and thus, poor material properties are assumed. It is noted that the same isotropic material model (TSRCM) is also used for the stone masonry. Rammed earth is used for the structural walls, both interior and exterior. Timber is used for the lintels over all the openings. The final reference model has two elements in the thickness direction of the wall and therefore, the resulting generated mesh has 31,264 nodes and 7,993 elements, see Figure 5. The roof is only considered as a distributed load on the top of the walls and the displacements of the elements at the base are fully restrained. The total mass of the model is 150 tons.

The rammed earth and the stone masonry are considered to present nonlinear behavior, while for the timber only the elastic properties are considered, as the structural nonlinearities are not expected to concentrate there. For the timber lintels, an elasticity modulus of $10 \mathrm{GPa}$ and a Poisson's ratio of 0.2 were used [27]. Regarding the stone masonry elastic properties, a modulus of elasticity of $1500 \mathrm{MPa}$ and a Poisson's ratio of 0.2 were adopted. Its compressive strength and specific weight were obtained from reference values given by the Italian code [32], assuming the lowest quality masonry class, an irregular rubble stone masonry composed of rubble and irregular stone units of different sizes and shapes. The remaining nonlinear properties of the masonry were computed directly from the compressive strength, based on recommendations given by Lourenço [33]. The compressive fracture energy was obtained using a ductility factor of $1.6 \mathrm{~mm}$, which is the ratio between the fracture energy and the 
ultimate compressive strength. The tensile strength was estimated at $1 / 10$ of the compressive strength. Finally, an average value of $0.012 \mathrm{~N} / \mathrm{mm}$ is adopted for the mode I fracture energy.

Concerning the rammed earth material elastic properties, an elasticity modulus of $300 \mathrm{MPa}$ and a Poisson's ratio of 0.3 were used. A compressive strength of $1 \mathrm{MPa}$ was adopted, which seem to be in agreement with the scattered values observed in the literature, but acknowledging the relevance of a sensitivity analysis. The remaining nonlinear properties were again calculated directly from the compressive strength following the same recommendations [33]. The only difference with respect to the stone masonry lies in the value used for the mode I fracture energy. According to [30], the fracture energy of rammed earth should be increased in about ten times because rammed earth behaves more as a monolithic and less as a brittle material in comparison with stone masonry due to its broad particle size distribution, which includes large particles that may have a significant contribution for the interlocking at the crack surface, by promoting its roughness. A value of $0.1 \mathrm{~N} / \mathrm{mm}$ was adopted for this reason. Table 2 presents the material properties finally used for the analyses.

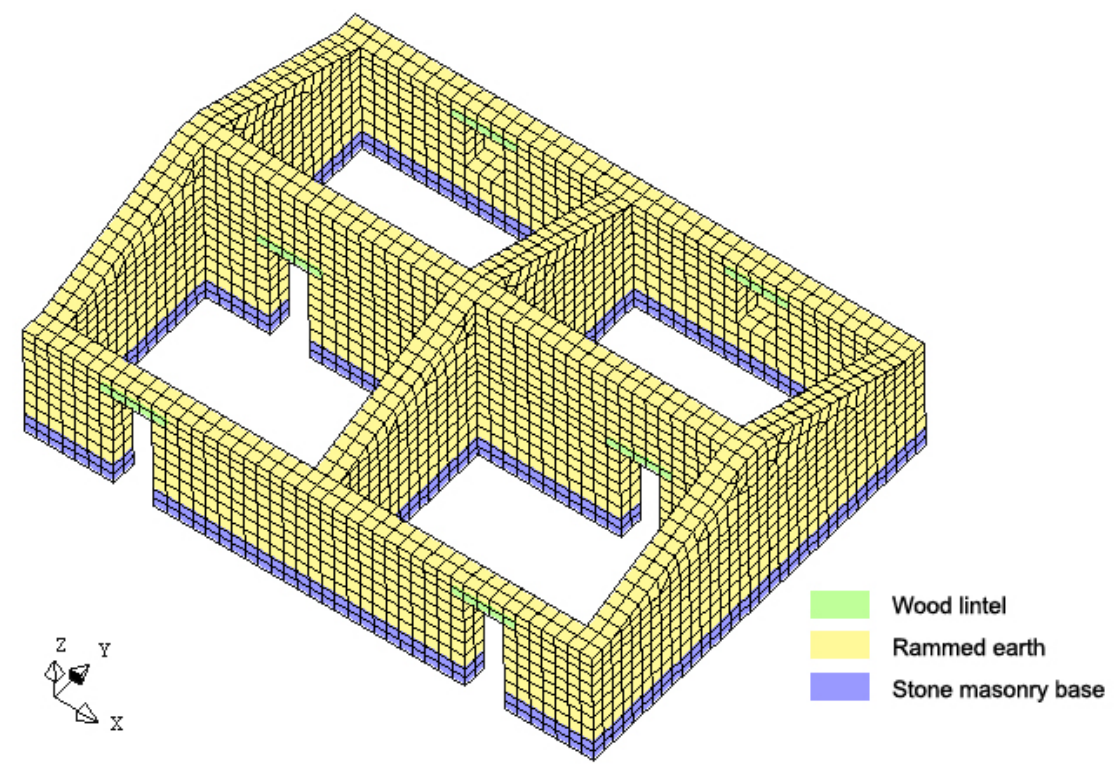

Figure 5: Numerical model: mesh categorized by materials

\begin{tabular}{lccccccccc}
\hline Material & $\mathrm{E}(\mathrm{MPa})$ & $v$ & $\mathrm{f}_{\mathrm{c}}(\mathrm{MPa})$ & $\mathrm{G}_{\mathrm{fc}}(\mathrm{N} / \mathrm{mm})$ & $\mathrm{f}_{\mathrm{t}}(\mathrm{MPa})$ & $\mathrm{G}_{\mathrm{fI}}(\mathrm{N} / \mathrm{mm})$ & $\beta$ & $\mathrm{W}\left(\mathrm{kN} / \mathrm{m}^{3}\right)$ \\
\hline Stone masonry & 1500 & 0.2 & 1.5 & 2.4 & 0.15 & 0.012 & 0.05 & 20 \\
Rammed earth & 300 & 0.3 & 1 & 1.6 & 0.1 & 0.1 & 0.05 & 20 \\
Timber & 10000 & 0.2 & - & - & - & - & - & 6 \\
\hline
\end{tabular}

Table 2: Mechanical properties adopted for the three materials used in the reference model

\subsection{Seismic performance of the reference model}

Before carrying out the numerical parametric study, the main dynamic characteristics of the reference model were obtained, showing that most of the modes are associated with local deformations, involving only specific structural elements at a time and that there is no global modes affecting the whole structure. This effect is enhanced by the fact that the roof is not modeled and the walls get to vibrate independently. The first modes are associated with local out-of-plane deformations of the walls in the Y direction, particularly the taller inner walls, less resistant to local deformations, see Figure 6. 

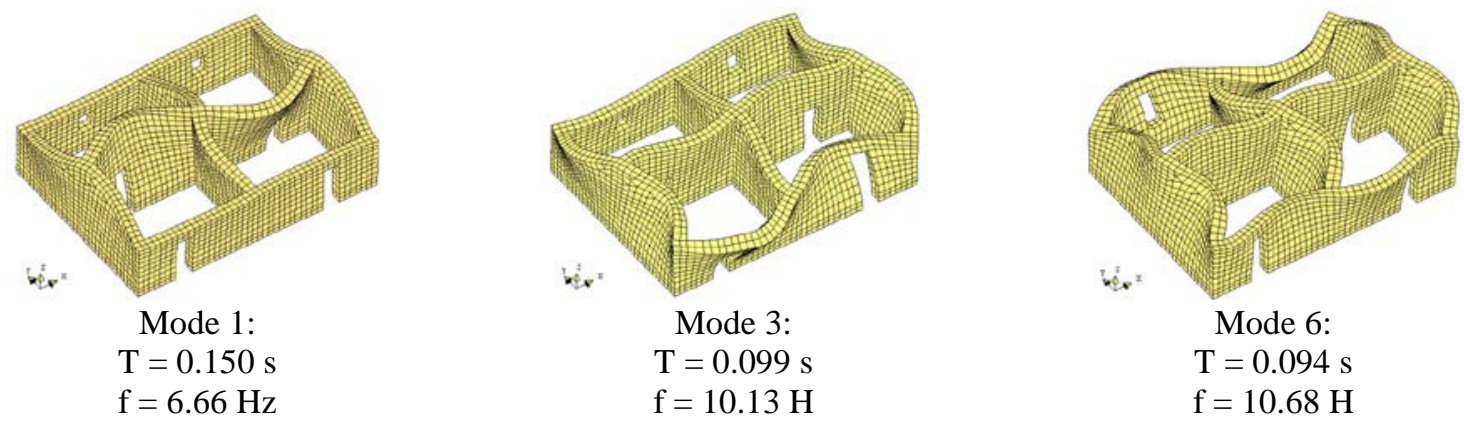

Figure 6: Shape of the first, sixth and sixth mode of the reference building

A nonlinear static (pushover) analysis was performed on the reference building, which is a common procedure used for the seismic assessment of buildings. First, only the dead weight and the distributed load on top of the walls, simulating the roof, are considered. After that, an incremental monotonic loading proportional to the mass is applied on the structure in the main horizontal directions (X and Y), as recommended by [34] for masonry structures. Only the positive directions are considered, since the behavior of the building is practically symmetric.

Figure 7 shows the capacity curve for the reference building in both horizontal directions. The analysis shows that the structure capacity is higher than could have been expected for this kind of buildings, obtaining maximum load coefficients of around $0.8 \mathrm{~g}$ in $+Y$ direction and over 1.1g in $+\mathrm{X}$ direction. This might be due mainly because the structural elements of the buildings are considered to be perfectly connected between them, avoiding their premature local out-of-plane collapse. Nevertheless, results were deemed satisfactory for the purpose of the study, which is a comparative analysis between different geometric and structural characteristics.

Figure 7 also shows the evolution of the maximum principal strains in the building in both $+\mathrm{X}$ and $+\mathrm{Y}$ direction, which can be used as a cracking measure. As could be expected, the parts of the building presenting more damage are the middle walls because they are higher than the rest and show flexural vertical cracks in the mid-span. However, the main damage is located at the connections between perpendicular walls. Horizontal cracking at the stone base is also substantial, as well as in the connection between both materials. In the case of the pushover analysis in $+\mathrm{X}$ direction, the middle interior walls present a clear in-plane failure.
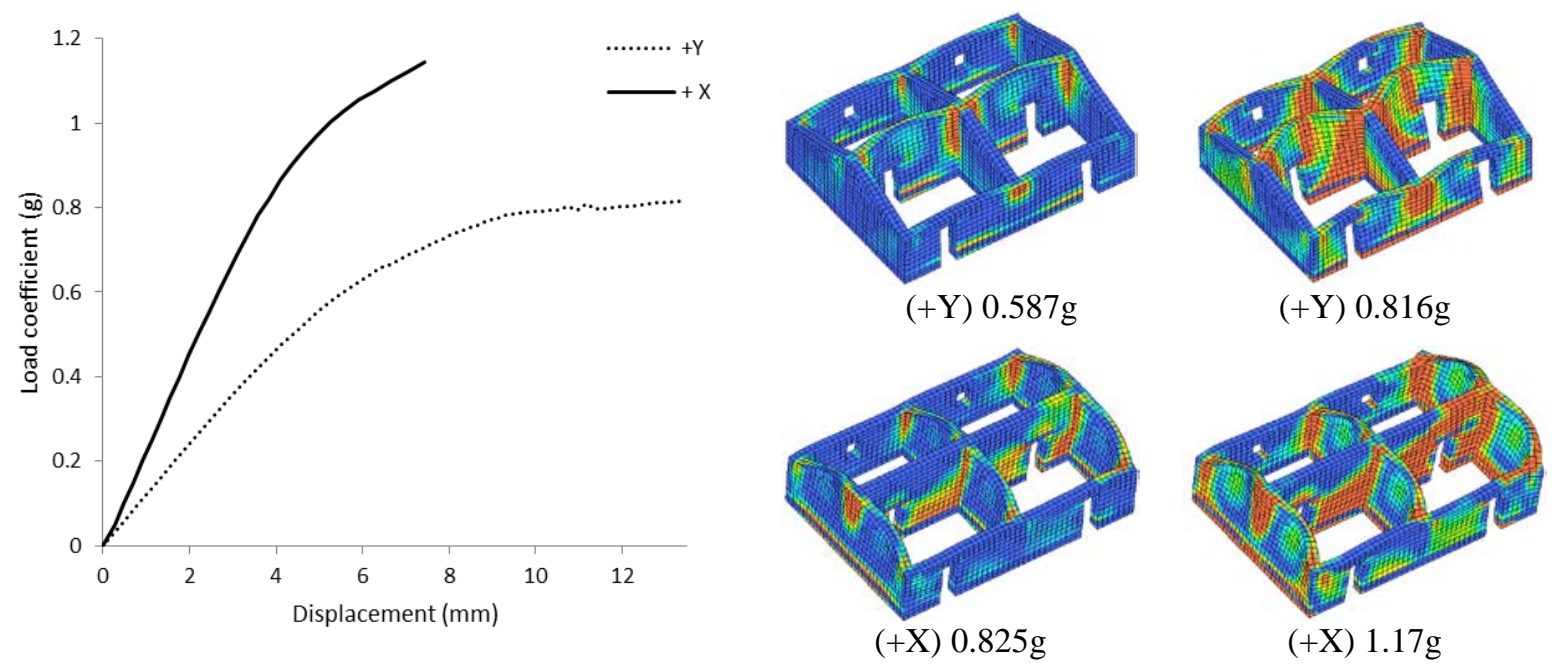

Figure 7: Capacity curve of the pushover analyses on the reference building and evolution of maximum principal strains along the building depicted on deformed mesh for the analysis in booth $+\mathrm{X}$ and $+\mathrm{Y}$ direction 


\section{NUMERICAL PARAMETRIC ANALYSIS}

Numerical nonlinear parametric analyses were defined in order to assess the influence of the different parameters selected and in order to understand in a more detailed way the seismic behavior of this typology. Therefore, the initial configuration of the reference model was changed in terms of geometry and construction characteristics and new models were built according to the parameters. The comparison between the new models and the reference one is made in terms of capacity curves. This approach intends to identify the most relevant parameters before addressing their calibration, required for the development of a seismic vulnerability assessment methodology. Table 3 shows the comparison, in terms of capacity curves, of the parameters that seem to have more influence in the building seismic response.

For example, the analysis assessing the influence of the plan configuration, particularly the influence of an irregular shape configuration, is shown. Particularly, it can be observed that when those parts of the building projecting have a significant dimension, such as in the case of building P2b_1, the capacity of the building decrease, probably due to the fact that these independent cells are freer to deform and allow some torsion effects to occur.

Parameters P4 and P5, which take into account the wall slenderness and the maximum span between walls shows an important difference in terms of peak loads. With respect to P4, when the height of the walls increases (P4_1 and P4_2), the flexural damage and the damage at the connections between perpendicular walls also increase, both in the interior and the exterior walls. Another two models were built modifying the thickness of the inner walls, which are usually thinner than the exterior ones (P4_3 and P4_4). Expectedly, reducing this thickness decreases the seismic capacity of the building. With respect to P5, when the span covered by the walls is very large, the elements get to behave practically as free standing walls, reducing much more their horizontal resisting capacity.

The influence of the stone masonry base course in the seismic behavior of the building was also evaluated by constructing two more models. First, the stone base was completely removed and the walls were considered to be built only with rammed earth. A second model was built with the stone base reaching a height of $1.0 \mathrm{~m}$. The main difference in the results consists on the variation in the stiffness of the model, mainly resulting from the difference in stiffness between both materials, confirming its influence.

The type of roof has a decisive influence since the type of roof used has a direct influence on the geometry of the building. For instance, if a truss roof is considered, the height of the middle wall is significantly reduced, down to the same height as the exterior walls and, therefore, the capacity of the building may increase. On the other hand, these changes can lead to the formation of new vulnerable elements, such as the gable wall. The lack of a middle wall bracing the gable end wall increases the vulnerability of this element, which becomes highly susceptible to collapse. Therefore, the influence of this parameter, which affects mainly the geometry, should be carefully assessed, particularly when evaluating those roof configurations that exert a thrust on the walls (P8a_2).

Another type of situation was considered regarding the wall-to-roof connections and another model was built simulating proper coupling between the parallel walls (P8b_1). A notable improvement in the seismic performance can be observed, particularly in the global stiffness of the model, since the resisting walls now respond to the horizontal action simultaneously.

The influence of the relative position of the openings with respect to the wall edges and other openings was also confirmed. A reduction in the size of the resisting piers (model P10_2), because of openings too close to the edges of the wall especially affects the in-plane resistance of the walls and leads to a considerable decrease of the capacity in $+X$ direction. 

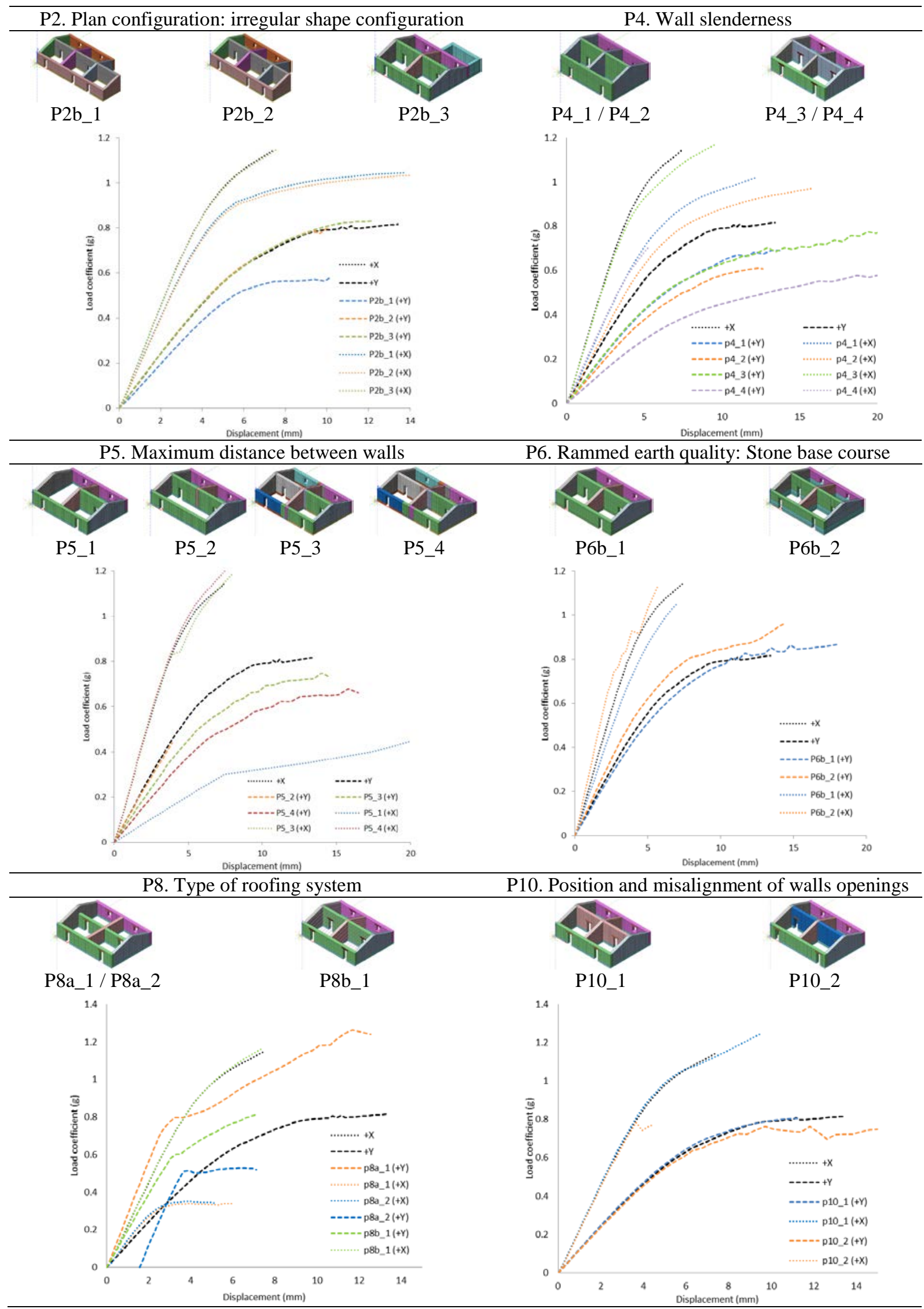

Table 3: Numerical parametric analyses carried out according to the parameters selected and comparisons in terms of capacity curves 


\section{CONCLUSIONS}

As part of an ongoing research that aims at the development of a seismic vulnerability assessment methodology of vernacular architecture, a numerical parametric study was carried out using pushover analysis proportional to the mass. The objective was to evaluate the variation of the seismic response adopting changes in the geometrical and construction characteristics of a Portuguese vernacular typology, consisting of rammed earth buildings.

Different parameters that were assumed to have a relevant influence in the seismic behavior were selected adjusted for the specific building typology studied. Construction aspects such as the plan configuration, the wall slenderness, the distance between walls and the relative position of the openings were among those considered. A reference model was first built, trying to effectively represent this vernacular typology, gathering common architectural characteristics. The model was constructed with DIANA software and the material properties used were obtained from the literature. Different models were then built adopting changes in the dimensions and construction characteristics according to those parameters selected.

Nonlinear static (pushover) parametric analyses were carried out and a comparison between the seismic performance of the reference model and the rest of the models was made, in terms of capacity curves. The results obtained confirm that the parameters selected have a relevant influence in the seismic behavior of the building. The results of the analysis of the reference building show that the building is more sensitive to out-of-plane failure, which can be expected due to the height to thickness ratio of the rammed earth walls assumed. The interior walls present more vulnerability as well because of their bigger height. The points of connection between orthogonal walls are also very vulnerable, showing big concentration of stress. This is particularly important given the fact that a perfect connection between the walls was assumed in this first set of analyses. This is not usually true for this type of buildings, which are many times characterized by poor wall-to-wall connections. The parameter addressing this characteristic assumes a greater importance for later analyses.

Following these analysis aimed at understanding the seismic behavior of this construction typology and the influence of certain specific construction characteristics, the calibration of the weights of the parameters need to be carried out at a further step, in order to develop the seismic vulnerability assessment methodology. Finally, another important future step will be the modeling of the distinct retrofitting solutions identified that are commonly applied in these buildings, such as buttresses. This will lead to a comparative analysis on the efficiency of the different strengthening techniques in improving the seismic global behavior of these vernacular buildings and will result in the calibration of one of the parameters proposed that is expected to be one of the main contributions of this research: the influence of traditional strengthening solutions in the reduction of the seismic vulnerability of vernacular architecture.

\section{ACKNOWLEDGEMENT}

The authors wishes to express their gratitude to the Portuguese Science and Technology Foundation (FCT) for the scholarship granted in the scope of the research project 'SEISMICV - Vernacular Seismic Culture in Portugal’ (PTDC/ATP-AQI/ 3934/2012).

\section{REFERENCES}

[1] M. Correia, G. Carlos, S. Rocha, P.B. Lourenço, G. Vasconcelos, H. Varum, SEISMICV: Vernacular seismic culture in Portugal. M. Correia, G. Carlos, S. Rocha eds. Vernacular Heritage and Earthen Architecture: Contributions for Sustainable Development. Taylor \& Francis Group, London, U.K., 663-668, 2014. 
[2] F. Ferrigni, S. Lorenzello, à la recherché des anomalies qui protégent. Conseil de l’Europe et Centre Universitaire Européen pour les Biens Culturels, Ravello, Italy, 1990.

[3] M. Correia, J. Merten, Preliminary Report of the Local Seismic Culture in Portugal. Taversism Project - Atlas of Local Seismic Cultures, EUCCH, Ravello Italy, 2001.

[4] V.J. Moreira. Sismicidade Histórica de Portugal Continental. Revista do Instituto Nacional de Meteorologia e Geofísica, Março, 1984.

[5] J.M.D. Mascarenhas, Baixa Pombalina, Algumas Inovações Técnicas. $2^{\circ}$ Encontro Sobre Conservação e Reabilitação de Edifícios, LNEC, Lisboa, Portugal, 1994.

[6] A.A.P., Arquitectura Popular em Portugal, $3^{a}$ Edição. Associação dos Arquitectos Portugueses, Lisboa, Portugal, 1988.

[7] G. Vasconcelos, P.B. Lourenço. Experimental characterization of stone masonry in shear and compression. Construction and Building Materials, 23(11), 3337-3345, 2009.

[8] G. Vasconcelos, P.B. Lourenço. In-Plane Experimental Behavior of Stone Masonry Walls. Journal of Structural Engineering (ASCE), 135(10), 1269-1278, 2009.

[9] H. Varum, A. Figueiredo, D. Silveira, T. Martins, A. Costa. Outputs from the research developed at the University of Aveiro regarding the mechanical characterization of existing adobe constructions in Portugal. Revista Informes de la Construcción, 63(523), 127-142, 2011.

[10] F. Neves, A. Costa, R. Vicente, C.S. Oliveira, H. Varum. Seismic vulnerability assessment and characterisation of the buildings on Faial Island, Azores. Bull. Earthquake Eng., 10(1), 27-44, 2012.

[11] M. Correia, Metodología Desarrollada para la Identificación en Portugal de Arquitectura Local Sismo Resistente. SismoAdobe2005, Seminario Internacional de Arquitectura, Construcción y Conservación de Edificaciones de Tierra en Áreas Sísmicas, Lima, Perú, 2005.

[12] J. Fernandes, R. Mateus, Energy efficiency principles in Portuguese vernacular architecture. International conference BSA 2012, Porto, Portugal, 2012.

[13] M.R. Degg, J. Homan. Earthquake vulnerability in the Middle East. Geography, 90(1), 54-66, 2005.

[14] S.J. Halvorson, J.P. Hamilton. Vulnerability and the Erosion of Seismic Culture in Mountainous Central Asia. Mountain Research and Development, 27(4), 322-330, 2007.

[15] R. Vicente, S. Parodi, S. Lagomarsino, H. Varum, J.R.M. Silva. Seismic vulnerability and risk assessment: case study of the historic city centre of Coimbra, Portugal. Bulletin of Earthquake Engineering, 9(4), 1067-1096, 2011.

[16] G.M. Calvi, R. Pinho, G. Magenes, J.J. Bommer, L.F. Restrepo-Vélez, H. Crowley. Development of Seismic Vulnerability Assessment Methodologies Over the Past 30 Years. ISET Journal of Earthquake Technology, 43(472), 75-104, 2006.

[17] D. Benedetti, V. Petrini. Sulla vulnerabilità di edifici in muratura: proposta di un método di valutazione. L'industria delle Costruzioni, 149(1), 66-74, 1984.

[18] GNDT, Scheda di esposizione e vulnerabilità e di rilevamento danni di primo livello e secondo livello (muratura e cemento armato). Gruppo Nazionale per la Difesa dai Terremoti (GNDT), Roma, Italia, 1994. 
[19] T.M. Ferreira, R. Vicente, J.R.M. Silva, H. Varum, A. Costa. Seismic vulnerability assessment of historical urban centres: case study of the old city centre in Seixal, Portugal. Bulletin of Earthquake Engineering, 11(5), 1753-1773, 2013.

[20] M. Correia, Taipa no Alentejo. Argumentum, Lisboa, Portugal, 2007.

[21] G. Minke, Manual de construcción para viviendas antisísmicas, $2^{a}$ Edición. Universidad de Kassel, Alemania, 2001.

[22] M. Blondet, M.G. Villa García, S. Brzev, A. Rubiños, Earthquake-Resistant Construction of Adobe Buildings: A Tutorial. Earthquake Engineering Research Institute (EERI), 2011.

[23] J. Bothara, S. Brzev, A Tutorial: Improving the Seismic Performance of Stone Masonry Buildings. Earthquake Engineering Research Institute (EERI), 2012.

[24] Q.-B. Bui, J.-C. Morel, S. Hans, N. Meunier. Compression behavior of non-industrial materials in civil engineering by three scale experiments: the case of rammed earth. Materials and Structures, 42(8), 1101-1116, 2008.

[25] P.A. Jaquin, Analysis of Historic Rammed Earth Construction. Ph.D. Thesis, Durham University, U.K., 2008.

[26] A.M. Braga, J.M.C. Estêvão, Os sismos e a construção em taipa no Algarve. Sísmica 2010 $8^{\circ}$ Congresso de Sismologia e Engenharia Sísmica, Aveiro, Portugal, 2010.

[27] M.I. Gomes, M. Lopes, J. de Brito. Seismic resistance of earth construction in Portugal. Engineering Structures, 33(3), 932-941, 2011.

[28] Q. Angulo-Ibáñez, Á. Mas-Tomas, V. Galvañ-Llopis, J.L. Montesinos. Traditional braces of earth constructions. Construction and Building Materials, 30, 389-399, 2012.

[29] R. Gallego, I. Arto, Evaluation of Seismic Behavior of Rammed Earth Structures. Mileto, Vegas, García-Soriano, Cristini eds. Versus2014, International Conference on Vernacular Heritage, Sustainability and Earthen Architecture. Taylor \& Francis Group, London, U.K., 2014.

[30] L. Miccoli, D.V. Oliveira, R. Silva, U. Müller, L. Schueremans. Static behaviour of rammed earth: experimental testing and finite element modelling. Materials and Structures, 2014.

[31] TNO, DIsplacement method ANAlyser (DIANA). User's manual, Release 9.4., Netherlands, 2009.

[32] NTC08, Circolare del Ministero delle Infrastrutture e dei Transporti 2 Febbraio 2009, n. 617. Istruzioni per l'applicazione delle nuove norme tecniche per le costruzioni di cui al Decreto Ministeriale 14 gennaio 2008. Suppl. Ordinario n. 27 alla G.U. n. 47 del 2602-2009, 2009.

[33] P.B. Lourenço, Recent advances in masonry structures: micromodelling and homogeneization. U. Galvanetto, M.H. Ferri Aliabadi eds. Multiscale modeling in solid mechanics: computational approaches. Imperial College Press, London, U.K., 251-294, 2009.

[34] P.B. Lourenço, N. Mendes, L.F. Ramos, D.V. Oliveira. On the analysis of masonry structures without box behavior. International Journal of Architectural Heritage: Conservation, Analysis, and Restoration, 5(4), 369-382, 2011. 